CERENKOV COUNTERS AT ISABELLE +

\title{
A. Etkin
}

Brookhaven National Laboratory

I. Kostoulas

Michigan State University

D.W.G.S. Leith

Stanford Linear Accelerator Center

and

R. Thun

University of Michigan

The following is a brief summary of our study of Cerenkov counters for ISABELLE. This study was certainly not exhaustive and was meant primarily to suggest future detector development.

The most simple cerenkov counters that can be used are threshold counters where the light is focussed on phototubes. A likely application of these devices at ISABELLE will occur in large-angle, small-aperture magnetic spectrometers for the measurement of particle yields at large $p_{T}$. Three threshold counters, such as those used in a Fermilab experiment, ${ }^{1}$ will provide complete $\pi-K-p$ separation in the range from $7-20 \mathrm{GeV} / \mathrm{c}$. This $\mathrm{p}_{\mathrm{T}}$ range is well matched to the expected luminosity and particle yields at ISABELLE, The use of standard threshold cerenkov counters in other application appears less attractive. For example, at small angles where particle momenta extend to $400 \mathrm{GeV} / \mathrm{c}$ very long counters are required since their length scales with the square

1. D. Bintinger, R.A. Lundy, D.D. Yovanovitch, C.W. Akerlof, P. Alley, D, Koltick, R.L. Loveless, D.I. Meyer, R. Thun, W.R. Ditzler, D.A. Finley, F.J. Loeffler, E.I. Shibata, and K.C. Stanfield, Phys, Rev, Lett. 37 , 732 (1976). 


\section{DISCLAIMER}

This report was prepared as an account of work sponsored by an agency of the United States Government. Neither the United States Government nor any agency Thereof, nor any of their employees, makes any warranty, express or implied, or assumes any legal liability or responsibility for the accuracy, completeness, or usefulness of any information, apparatus, product, or process disclosed, or represents that its use would not infringe privately owned rights. Reference herein to any specific commercial product, process, or service by trade name, trademark, manufacturer, or otherwise does not necessarily constitute or imply its endorsement, recommendation, or favoring by the United States Government or any agency thereof. The views and opinions of authors expressed herein do not necessarily state or reflect those of the United States Government or any agency thereof. 


\section{DISCLAIMER}

Portions of this document may be illegible in electronic image products. Images are produced from the best available original document. 
of the momentum. Another example is a large-aperture spectrometer where the requirements of good segmentation and likely pressurization of counters present formidable mechanical problems. A more extensive discussion of standard Cerenkov techniques for ISABELIE is given in a separate paper by $K$. Foley. 4

More compact and powerful Cerenkov counter systems than those outlined above can be achieved if the Cerenkov angle defined by $\cos \theta=1 / n \beta$ is measured. Particle identification by this technique requires correlatable measurements of charged particle tracks, momenta, and associated Cerenkov radiation. Detectors with such a capability have been suggested by seguinot and ypsilantis ${ }^{2}$ based on photoionizing devices (to be discussed below) and by kostoulas and collaborators ${ }^{3}$ who propose the use of image intensifiers and CCD arrays. In the latter scheme, Cerenkov light generated in freon 12 or $S F_{6}$ is focussed on an image intensifier with a gain of $10^{4}-10^{5}$. Light from the fast phosphor output of the intensifier is then refocussed on a CCD array which employs, for the sake of high-rate operations, two parallel outputs per cell which are cleared alternately with a frequency of $0.5 \mathrm{MHz}$. With this system $2 \sigma \pi-K$ separation is expected between 5 and 65 GeV and $K-p$ separation between 10 and $100 \mathrm{GeV}$.

As stated above, Seguinot and Ypsilantis have suggested a Cerenkov counter where the radiation is detected by a photoionizing

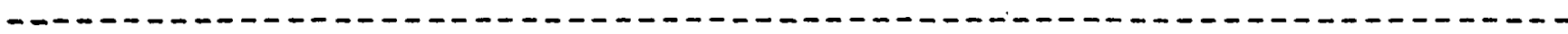

2. J. Seguinot and T. Ypsilantis, Nucl. Instr. Meth. 142, 377 (1977).

3. Fermilab Proposal 556.

4. K.J. Foley, "Conventional' Cerenkov counters at Isabelle", these proceedings. 
device. In this scheme the radiator is a spherical shell of inner and outer radius $R / 2$ and $R$ respectively, with the inner surface being the window of the photoionization detector". If the particles come from a point source then the cerenkov light. is focussed by the spherical mirror (radius-R) into a ring at the window of the photoionization detector. The photoelectrons are detected by needles run as Geiger counters.

We believe that the significance for ISABELLE of the Seguinot and Ypsilantis approach lies more in the general nature of the technique than in the specific features of their proposal. The significant idea is to detect ultraviolet cerenkov light by photoionization and gas multiplication of the resultant electron. The potential advantages of such Cerenkov counters are very attractive. They include:

1) Improved photon statistics because of higher quantum efficiency and possibly broader frequency acceptance. This allows a reduction in cerenkov counter dimensions which is clearly important for many ISABELLE detector configurations.

2) Detection of Cerenkov light with high spatial resolution because of the use of relatively cheap wire amplification systems. The measurement of particle velocities by the determination of Cerenkov angles is thus made feasible.

3) Operation of threshold counters in high magnetic fields. Wire-based amplification systems operate in much higher fields than do phototubes. 
4. Ease of segmentation of large aperture threshold Cerenkov counters.

For successful application of this idea we need a cerenkov media transparent to the far ultraviolet, a good ultraviolet window, a photoionizing gas with high ultraviolet absorption, and a readout system. There is a need for a considerable amount of research and development work before we can have practical components, as is indicated in the following brief discussion of the present state of the individual components. Very few Cerenkov media are known to be suitable for these detectors. Most substances (including air and water vapor:) are opaque in the far ultraviolet. The inert elements are transparent as is $\mathrm{N}_{2}$. For argon and $\mathrm{N}_{2}$ at STP, $\mathrm{n-l} \approx 56 \times 10^{-5}$ at around $10 \mathrm{eV}$. It should be noted that dispersion which has not been well measured or understood in the vacuum ultraviolet region, must be carefuliy considered in the design of a Cerenkov counter. We therefore recommend a program to study these materials and search for and catalog other Cerenkov media, in order to more fully exploit the photoionizing. Cerenkov counter.

Presently used window materials are LiF, MgF 2 and plastic films. Lif has the highest known transmission cutoff at $11.8 \mathrm{eV}$. Although it is sensitive to moisture and becomes opaque under intense ionizing radiation, Lif could be a practical window because the transmission properties can be restored by baking (which could even be done in situ). $M g F_{2}$ is much more resistant to moisture and radiation and still has a high cutoff energy at 
$10.8 \mathrm{ev}$. Very thin films of plastic have been used and may prove useful for reasonably sized counters. Because of the short range of the photons in the ionizing gas it is necessary "to have the cathode plane very close to the window. This requirement and the difficulty of making large windows out of any of the previously mentioned materials dictates that new construction techniques or new materials be developed. One suggestion is to deposit or grow window material on a wire mesh that would serve as the cathode, it remains to be seen if good optical properties can be obtained this way.

The photoionizing gas must have several properties. It must be a good proportional counter gas with the usual quenching ability and it must of course have a large.ionization cross section for ultraviolet light. Seguinot and Ypsilantis have shown that an argon-CO $\mathrm{C}_{2}$ mixture doped with benzene satisfies these requirements. Benzene has a photoionization threshold of $9.2 \mathrm{eV}$. A number of organic substances (see Bibliography and Fig. I) are known to have thresholds appreciably below this (down to about $6 \mathrm{ev}$ ). A major effort should be made to study their feasibility in photoionizing detectors since the number of cerenkov photons available for detection is proportional to the frequency interval between ionization threshold and window cutoff.

If one is only interested in having one dimensional readout of the photon position (such as in a threshold counter), one can use standard multiwire proportional chamber techniques to detect the photoelectron. If two dimensional information is required 
(such as to determine the cerenkov angle) then techniques such as charge division, delay line readout of induced cathode signals, or readout of individual cathode pads might be used. These techniques suffer from disadvantages'such as poor time resolution, poor two electron resolution and high expense. The suggestion by $J$. Seguinot and $T$, Ypsilantis of using many small Geiger celis with needles is appealing but it has proven difficult to construct a large array of needles. with a uniform plateau. Also the electron collection efficiency of simple needle arrays is low ( 10 ) and some focussing structure must be developed to get high efficiency. Another way to have two dimensional readout is the suggestion of Leith and collaborators to use a segmented anode wire readout in which the PWC anode is made in short lengths mounted on a printed circuit, each length being read out individually. This idea requires further. investigation to see if large chambers can be built that are stable and reasonable in cost.

In summary we would like to emphasize the need for a substantial research effort to be mounted in order to insure that cerenkov counters utilizing photoionization are fully exploited. In the hope of stimulating interest in this topic we are including a Bibliography of relevant literature. We would like to thank N. Kublin for her extensive help in the preparation of the Bibliography.

+ Work performed, in part, under the auspices of the United States Department of Energy under Contract No. EY-76-C-02-0016. 
BIBLIOGRAPHY

Cerenkov Counters (General)

1. G. Bowden, R. Field, R. Lewis, C, Hoard, K. Skarpaas,

P. Baker, Nucl. Instr, \& Meth. 138, 77 (1976).

2. J, Litt and R. Meunier, Annual Review of Nuclear science 23 (1973)

3. D. Yovanovitch, D. Rust, I. Ambats, Nucl, Instr. \& Meth, 94, $477(1971)$

\section{Cerenkov Counters (Ultraviolet)}

1. P. Baillon, Y. DeClais; M. Ferro-Luzzi, B. French, P. Jenni, J.-M. Perreau, J. Seguinot, T. Ypsilantis, Nucl. Instr. \& Meth. 126, $13(1975)$.

2. E. Garwin, Y. Tomkiewicz, D. Trines, Nucl. Instr. \& Meth. 107, $365(1973)$.

3. M. Piestrup, R. Powell, G. Rothbart, C, Chen, R, Pantell, Applied Physics Letters 28, 92 (1976).

4. J. Seguinot and T. Ypsilantis, Nucl. Instr. \& Meth. 142 $377(1977)$.

General Surveys of the Ultraviolet

1. E. Inn, Spectrochimica Acta 7,65 (1955).

2. E.D. Koch, R. Haensel, C. Kunz, Editors, Vacuum Ultraviolet Radiation Physics, Proc, 4th Int, Conf. of Atomic \& Molecular Physics \& Spec. Commission, Int. Union of Pure \& Applied Physics, Pergamon Press (1974). 
General surveys of the Ultraviolet (continued)

3. I, Koller, Ultraviolet Radiation, J. Wiley \& sons, Inc,; New York (1965).

4. A. Samson, Techniques of Vacuum Ultraviolet spectroscopy, J. Wiley \& Sons, Inc., New York (1967).

5. A. Zaidel and E. Shreider, Vacuum Ultraviolet spectroscopy, Ann Arbor-Humphrey Science Publishers, (1970).

\section{Mirror Coatings}

1. M. Adriaens and B, Feuerbacher, Applied optics 10,958 (1971).

2. B, Bates and D, McCartney, Applied Optics 15, 2216 (1976).

3. P. Berning, G. Hass, R. Madden; Journal of the optical society of America $\underline{50}, 586$ (1960).

4. A, Bradford, G. Hass, J. Osantowski, A, Toft, Applied optics 8. $1183(1969)$.

5. L, Canfield, G, Hass, J. Waylonis, Applied optics $\underline{5}, 45$ ( 1966 ).

6. J. Cox, G. Hass, J. Waylonis, Applied optics ㄱ, 1535 (1968).

7. G. Hass and R. Tousey, Journal of the optical: society of. America 49,593 (1959).

8. W. Hunter, J. Osantowski, G. Hass, Applied Optics 10, 540 (1971).

9. E. Hutcheson, G. Hass, J. Cox, Applied Optics 11, 2245 (1972).

10. A. Malherbe, Applied Optics 13, 1275 (1974).

11. A, Malherbe, Applied Optics 13, 1276 (1974).

12. E. Spiller, Applied Optics 15, 2333 (1976). 


\section{Organics, Photoionization}

1. F. Bovey and S, Yanari, Nature 186, 1042 (1960).

2. Y. Nakato, M. Ozaki, A. Egawa, H. Tsubomura, Chemical Physics Letters $\underline{9}, 615(1971)$.

3. R. Schoen, The Journal of Chemical Physics 37, 2032 (1962).

4. B. Vodar, Journal of Quantitative spectroscopy and Radiative Transfer $2,393(1962)$.

5. K. Watanabe, T. Nakayama, J. Mottl, Journal of Quantitative Spectroscopy and Radiative Transfer 2 , 369 (1962).

Photoionization and Absorption of the Elements (particularly gases)

1. B. Barnes, Applied Optics $\underline{5}, 1685$ (1966).

2. J. Barrett and A. Manse11, Nature 187, 138 (1960).

3. M. Camac, Journal of Chemical Physics 34,448 (1961).

4. R. Ditchburn, Proceeding of the Royal society A $236 ; 216$ (1956).

5. R, Hudson and L. Kieffer, Atomic Data 2, 205 (1971).

6. E. Inn, K. Watanabe, M. Zelikoff, Journal of Chemical Physics 21, 1648 (1953).

7. G. Marr, Photoionization Processes in Gases, Academic Press $(1967)$.

8. K. Watanabe and F. Marmo, The Journal of Chemical Physics 25 , $965(1956)$.

9. G. Weissler, Handbuch der Physik XXI, 321 (1956).

Photoionization and Absorption of the Elements (Particularly gases) Extreme Ultraviolet

1. R. Carlson, D. Judge, M. Ogawa, L. Lee, Applied optics 12 , 409 (1973). 
Photoionization and Absorption of the Elements (Particularly gases) Extreme Ultraviolet (Continued)

2. W. Garton; J. Connerade, M. Mansfield, J, Wheaton, Applied Optics 8 , 919 (1969).

3. R.E. Huffman, Y. Tanaka, J.C. Larrabee, Journal of Chemical Physics 39, 902 (1963).

4. G. Marr and J. West, Atomic Data and Nuclear Data Tables 18 , $498(1976)$

5. B, Vodar, Journal of Quantitative Spectroscopy and Radiative Transfer 2 , 393 (1962).

6. G. Weissler, Journal of Quantitative spectroscopy and Radiative Transfer. $2,383(1962)$.

7. J. West and G. Marr, Proceedings of the Royal society A 349 , 397 (1976).

Refractive Indices of Gases

1. A. Bideau-Mehu, Y Guern, R, Abjean, A. Johannin-Gilles, Optical Communications 16 , 186 (1976).

2. D, Heddle, R, Jennings, A. Parsons, Journal of the optical Society of America 53, 840 (1963).

Ultraviolet Detectors

1. G. Carruthers; Applied optics 14, 1667 (1975).

2. D. Heath and J: McElaney, Applied Optics Z, 2049. (1968).

3. H. Rast and H. Caspers, Applied Optics 6, 1577 (1967).

4. S. Shaw, G, Grant, W. Gunter Jr., Applied optics 10,2559 (1971). 
(Extreme) UItraviolet Detectors

1. L, Canfield, R, Johnson, K, Codling, R, Madden, Applied Optics $6,1886(1967)$.

2. L. Heroux, Applied Optics 7, 2351, (1968).

3. I. Lapson and J. Timothy, Applied Optics 12, 388 (1973).

4. J. Mack, F. Paresce, S. Bowyer, Applied Optics 15, 861 (1976).

5. T. Masuoka and T. Oshio, Japanese Journal of Applied Physics 15, $65(1976)$.

6. F. Paresce, Applied Optics 14, 2823 (1975).

7. J. Samson and G. Haddad, Journal of the optical society of America $64,47(1974)$.

8. A. Timothy, J. Timothy, A. Willmore, Applied optics $\underline{6}, 1319$ $(1967)$

Window Materials

1. A. Ballman, D. Dodd, N. Kuebler, R. Landise, D. Wood,. D. Rudd, Applied Optics 7,1387 (1968).

2. V. Chandrasekharan and H. Damony, Applied optics 7, 939 (1968).

3. V. Chandrasekharan and H, Damony, Applied Optics 7,687 (1968).

4. D. Heath and P. Sacher, Applied optics 5, 937 (1966).

5. L. Koller, Ultraviolet Radiation, J. Wiley \& Sons, Inc., New York (1965).

6. Landolt-Borstein, Zahlenwerte und Funktionen, 8 optisché Konstanten, springer-Verlag i962, p. 3-537.

7. S. Lange and $w$. Turner, Applied Optics 12, 1733 (1973).

8. A. Laufer, J, Pirog; J, McNesby, Journal of the optical society of America 55, 64 (1965): 


\section{Window Materials (Continued)}

9. D. McCarthy, Applied Optics 6 , 1896 (1967).

10. Y. Uchida, R. Kato, E. Matsui, Journal of the Quantitative spectroscopy and Radiative Transfer 2 , 589 (1962).

Windows (Extreme Ultraviolet)

1. K, Codling, R. Madden, W. Hunter, D. Angel, Journal of the Optical Society of America 56, 189 (1966).

2. W. Hunter, D. Angel, R. Tousey, Applied optics 4, 891 (1965).

3. W. Hunter, G. Steele, R. Gillette, Applied Optics 12, 2800 $(1973)$

4. H. O'Bryan, Journal of the optical society of America 22 , $739(1932)$. 
FIGURE CAPTION

Fig. 1. Ionization potential limit of various gases and ultraviolet transmission cutoff of window materials. 


\section{THIN FILMS}
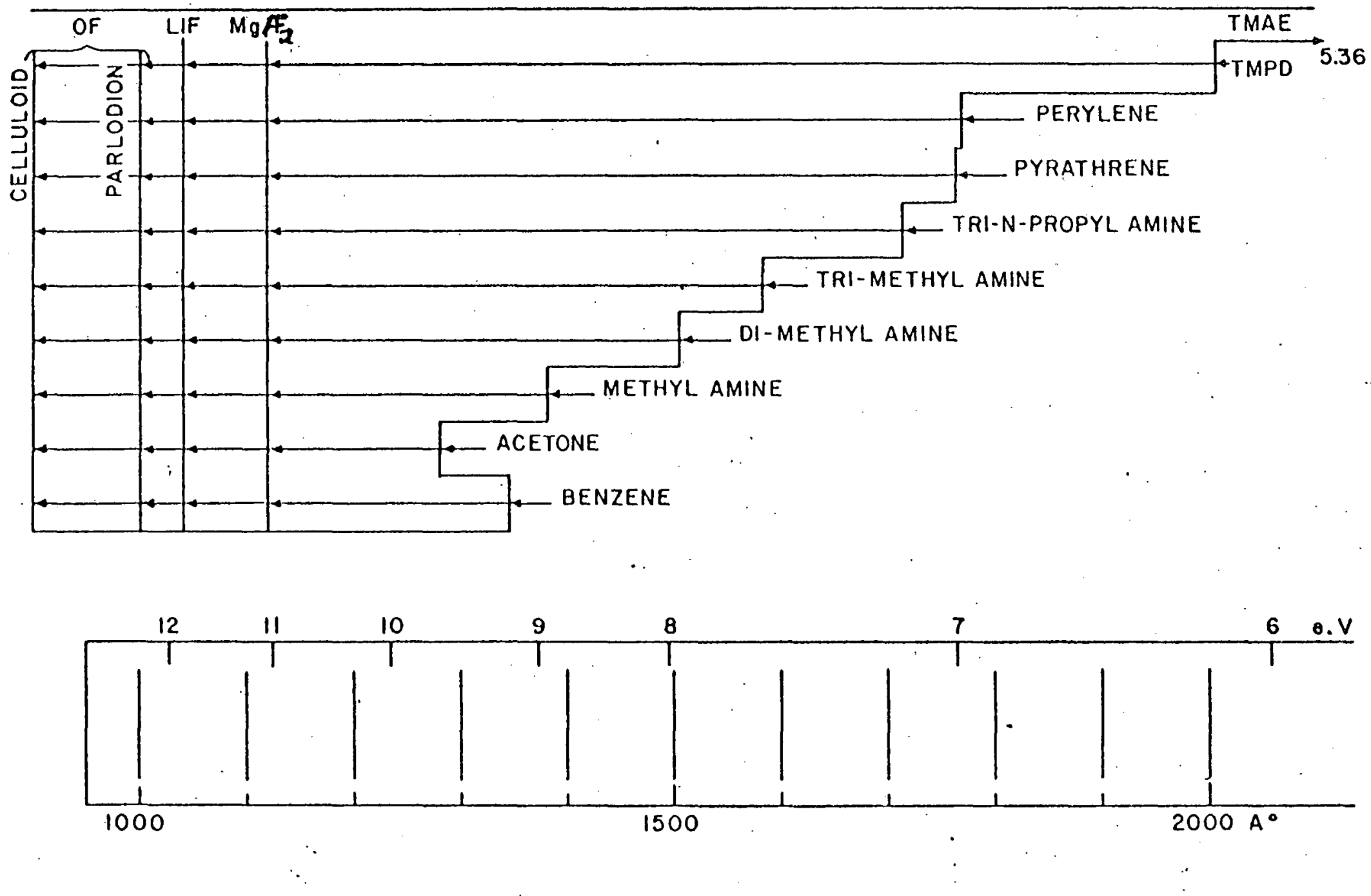